\title{
Incidence of udder cleft dermatitis (UCD) in dairy cows and risk factors for transitions to UCD
}

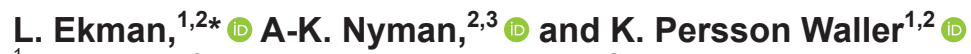 \\ ${ }^{1}$ Department of Animal Health and Antimicrobial Strategies, National Veterinary Institute, SE-75189 Uppsala, Sweden \\ ${ }^{2}$ Department of Clinical Sciences, Swedish University of Agricultural Sciences, SE-75007 Uppsala, Sweden \\ ${ }^{3}$ Växa Sverige, SE-10425 Stockholm, Sweden
}

\begin{abstract}
Udder cleft dermatitis (UCD) is a common skin condition in Swedish dairy cows, affecting the anterior parts of the udder. The main objective of this study was to investigate incidence rate and duration of UCD in a 1-yr longitudinal study. Other objectives were to investigate risk factors for transitions from being healthy to having mild or severe UCD, and from having mild UCD to having severe UCD, and associations between UCD and clinical mastitis, somatic cell count (SCC) and hock lesions. Seven herds were included in the study and visited 9 times each at 6 -wk intervals. At the visits, mild and severe UCD lesions, hock lesions, udder conformation traits, and hygiene scores were registered for each cow milked in the milking parlor. Information on breed, parity, days in milk (DIM), results from test milkings (milk production, SCC, and urea level), and veterinary treatments was also obtained. A UCD case was defined as one or several consecutive observations of UCD. The incidence and duration of UCD were described. Mixedeffect logistic regression models were used to analyze associations between potential risk factors and transitions to any type of UCD. Separate risk factor analyses were performed for transitions to mild and severe UCD. Associations with SCC, mastitis, and hock lesions were also analyzed with mixed-effect logistic regression models. The mean overall incidence of new UCD cases for all visits and herds was 0.5 cases per cow-year at risk. Risk factors associated with a higher risk of a transition to any type of UCD and mild UCD were breed (Swedish Red vs. Swedish Holstein), an indentation or fold at the fore udder attachment, and increasing DIM. In addition, a low milk urea level was associated with a lower risk of transition to any type of and mild UCD. Cows with previous mild UCD and high-yielding cows had increased risk for a transition to severe UCD. Cows
\end{abstract}

Received November 20, 2019

Accepted August 5, 2020.

*Corresponding author: lisa.ekman@slu.se that had an observed transition to severe UCD had an increased risk of veterinary-treated clinical mastitis within 6 wk after the UCD observation. No associations were found between UCD and SCC or hock lesions. The median observed duration of a UCD case was 12 wk, but most cases did not have an observed start or end during the study period. The observed duration of cases including severe UCD was longer than for cases involving only mild UCD. The high incidence and often long duration of UCD emphasize the need for preventive measures and treatment strategies.

Key words: ulcerative mammary dermatitis, intertrigo, skin ulcer, longitudinal, cattle

\section{INTRODUCTION}

Udder cleft dermatitis (UCD) is common among cows in Swedish dairy herds (Persson Waller et al., 2014; Ekman et al., 2018). The lesions are also seen in other countries, although few prevalence studies have been performed (Warnick et al., 2002; Hansen and Nissen, 2010; Olde Riekerink et al., 2014). Lesions appear at the fore udder attachment or between the udder halves and are of unknown etiology. Ranging from small, eczema-like skin changes to large, exudative lesions, UCD may cause pain and discomfort in affected animals. The lesions may be classified as mild or severe according to their appearance and size (Persson Waller et al., 2014; Bouma et al., 2016; Ekman et al., 2018).

Most studies on UCD epidemiology are cross-sectional, focusing on risk factors associated with having UCD (Olde Riekerink et al., 2014; Persson Waller et al., 2014; Ekman et al., 2018). Several such factors have been identified, but they explain only a small part of the variation in UCD prevalence. Udder conformation traits, such as fore udder attachment and udder depth, are important factors for UCD (Hansen and Nissen, 2010; Persson Waller et al., 2014; Ekman et al., 2018), as are parity, DIM, and production level (Persson Waller et al., 2014; Bouma et al., 2016; Ekman et al., 2018). Ekman et al. (2018) also found that risk factors differ 
between mild and severe UCD, indicating that mild and severe lesions should be investigated separately.

Longitudinal studies investigating incidence of new UCD, the progress and chronicity of lesions, and risk factors associated with the onset of UCD are lacking. However, Bouma et al. (2016) followed 5 Dutch dairy herds for 45 wk. The incidence of new cases of UCD was 1.94 cases per 100 cow-weeks at risk, and the risk for UCD was higher for cows in their third or higher parity. The risk also increased with DIM. Most lesions persisted for a long time (median duration $16 \mathrm{wk}$ ). Given the chronic nature of UCD lesions, it is possible that the risk factors for UCD identified in previous cross-sectional studies are not valid for the onset of new cases of UCD. Further longitudinal studies on risk factors for new UCD are therefore warranted.

Apart from a direct effect on animal welfare, UCD may be associated with other health problems, such as mastitis (Persson Waller et al., 2014) and hock lesions (Ekman et al., 2018). The reasons for these associations are not clear, but the presence of many bacterial species in UCD lesions may be one factor (Beattie and Taylor, 2000; Warnick et al., 2002; Sorge et al., 2019). Because the associations between UCD and mastitis and hock lesions have not been confirmed in other studies, further investigations are needed.

The aims of this study were to investigate the incidence of new UCD cases and risk factors associated with transitions from being healthy to having mild or severe UCD, and from having mild UCD to having severe $\mathrm{UCD}$, as well as to investigate the duration of $\mathrm{UCD}$, by following 7 Swedish dairy herds for $1 \mathrm{yr}$ in a longitudinal study. Additional aims were to investigate the relationships between UCD and other health problems, such as mastitis and hock lesions.

\section{MATERIALS AND METHODS}

\section{Herd Data}

Seven Swedish dairy cattle herds were enrolled in a longitudinal study based on the following inclusion criteria: UCD prevalence of 15 to $60 \%$ in a previous UCD study (Ekman et al., 2018), use of a milking parlor and loose housing system, and enrollment in the Swedish official milk recording scheme (Växa Sverige). In this study, the cow was the study unit, and the number of individual cows needed was estimated to be 787 to ensure enough cases of severe UCD. The sample size was calculated to find at least $9( \pm 2)$ severe UCD cases per 100 examined cows, with a 95\% CI, and the number of selected herds was a convenience sample to achieve around 800 individual cows. The herds selected were situated within $200 \mathrm{~km}$ from Uppsala, to facilitate herd visits. Participating farmers were asked not to use any topical treatments on UCD lesions during the ongoing study, which was according to their usual management.

\section{Herd Visits}

Each herd was visited 9 times, approximately every 6 wk during the 1-yr study period (April/May 2018 to April 2019), at morning or afternoon milkings. All herd visits were performed by the first author, who made the observations during milking, based on the side of the cow visible from the milking parlor. Hand-written protocols were used on site and later transferred to Excel spreadsheets (Microsoft Corp, Redmond, WA). Lesions were scored from 0 to 5 (Table 1 ), where $0-1$ corresponded to no UCD, 2 to mild UCD (small crusts, papules, or pustules, often in combination with redness of the skin and serum exudation), and 3-5 to severe UCD (large crusts, breach of skin integrity, or proliferations of the skin) in line with a previous study (Ekman et al., 2018). If the cow had more than one UCD lesion, the areas of the lesions were combined for the scoring of size, and the most severe lesion was used for scoring of severity.

All cows that were milked in the parlor were examined for UCD at the fore udder attachment and between the front quarters of the udder. A hand-held mirror and a flashlight were used to visualize the area of interest. Each cow was also scored for 3 udder conformation traits, hygiene, and presence of hock lesions. The udder conformation traits were udder depth (relation of the udder base to the hock; scale $1-3,1=$ udder base at

Table 1. Scoring of udder cleft dermatitis (UCD) used in the study

\begin{tabular}{|c|c|c|}
\hline $\begin{array}{l}\text { Detailed } \\
\text { scoring }\end{array}$ & Classification & Clinical appearance at the fore udder attachment or between the front quarters \\
\hline 0 & No UCD & No signs of UCD. \\
\hline 1 & No UCD & $\begin{array}{l}\text { Very mild skin changes, such as redness of the skin or a single papule or pustule in the area of the fore udder } \\
\text { attachment. }\end{array}$ \\
\hline 2 & Mild UCD & Small papules/pustules or crusts, in combination with 1 or several signs of score 1 ; total size of crusts $<5 \times 5$ cm. \\
\hline 3 & Severe UCD & Large crusts, with or without signs of scores $1-2$; total size of crusts, $\geq 5 \times 5 \mathrm{~cm}$. No open wound. \\
\hline 4 & Severe UCD & Open wound, with or without signs of scores $1-3$; total size of wound and surrounding crusts $<5 \times 5 \mathrm{~cm}$. \\
\hline 5 & Severe UCD & Open wound, with or without signs of scores $1-3$; total size of wound and surrounding crusts $\geq 5 \times 5 \mathrm{~cm}$. \\
\hline
\end{tabular}


or below hock level, $2=$ udder base $2-12 \mathrm{~cm}$ above hock level, $3=$ udder base more than $12 \mathrm{~cm}$ above hock level), fore udder attachment (angle between fore udder and abdominal wall; scale $1-3,1=$ angle $90^{\circ}$ or less, $2=$ angle around $120^{\circ}, 3=$ angle $160^{\circ}$ or more), and presence of an indentation or fold $(\mathbf{I} / \mathbf{F})$ at the fore udder attachment (yes or no; Ekman et al., 2018). The hygiene score was based on the hind leg above the hock and the side of the udder visible from the milking parlor, and had a scale of 1 to 3 , where $1=$ clean or stains of dirt (total area of dirt $<10 \mathrm{~cm}^{2}$ ), $2=1$ to 2 areas of dirt around $10 \mathrm{~cm}^{2}$, and $3=$ more than 2 stains of $10 \mathrm{~cm}^{2}$ or larger area of dirt (modified from Ekman et al., 2018). Hock lesions (hair loss, open wound, or crusts) were scored on the outside of the hock that was visible from the operating area of the milking parlor. In addition, individual cow data on breed, lactation number, DIM, and results from monthly test milkings of milk production $(\mathrm{kg} / \mathrm{d})$, milk SCC, and milk urea levels were obtained from the Swedish official milk recording scheme.

The results from the test milking closest in time before the herd visit (up to $31 \mathrm{~d}$ before) were allocated to the observation at that particular herd visit when available. Farmers were asked to register veterinary treatments of cows during the study period. Registrations from claw trimmers were also obtained when available.

\section{Statistical Analyses}

All statistical analyses were performed in Stata (release 15.1; StataCorp LLC, College Station, TX).

Data Editing. To correspond with previous definitions of UCD (Persson Waller et al., 2014; Ekman et al., 2018) and to avoid subgroups with small numbers of cows, in all analyses, UCD was classified as no, mild, or severe (Table 1). The prevalence of any and each type of UCD was calculated for each herd at each visit. In addition, the number of transitions in all directions, between healthy, mild, and severe UCD, was calculated.

Incidence of Observed New UCD Cases. The incidence rate of observed new UCD cases was defined as the number of new observations of any type of UCD divided by the total "cow-time at risk," standardized into new cases per cow-year at risk. This was calculated in Stata, using the stptime command (used to calculate person-time and incidence rates) after survival-time setting the data, with time defined as days after first observation for each individual cow, and any type of UCD as a single-failure event. The result from the stptime calculation (cases per cow-day at risk) was then transformed to cases per cow-year at risk by multiplying the rate by 365 . In addition, the subincidence rates of observed new cases of mild and severe UCD were calculated in the same way as for any type of UCD. However, for mild UCD, cows were censored if they got severe UCD, whereas for severe UCD, cows with mild UCD as well as cows with no UCD were included as cows at risk. Apart from the overall incidence for all herds and all visits combined, the within-herd incidence was also calculated for each herd. In all incidence calculations, a single cow could contribute to only 1 incident, even if she had recurrent cases of UCD.

Analyses of Risk Factors for Transitions to $U C D$. Risk factors for transitions to any type of, mild, or severe UCD were analyzed in 3 separate transition models. All models used mixed-effect logistic regression analysis, with herd and cow included as random effects (equal variances, all covariances zero), and the presence of UCD (yes or no) as a binary outcome.

In the data set used for analyzing transitions from healthy to affected by any type of UCD, observations where the cow had no UCD at the previous observation were included; thus, multiple observations per cow could be included in the models, if the cow had several observations of no UCD or if she had recurrent cases of UCD. Explanatory variables were first screened in univariable analyses for their association with a transition to UCD, and variables with $P \leq 0.2$ were kept for the multivariable analyses. Continuous variables were assessed for a linear association with the outcome, and, if no linear association was detectable, they were transformed into categorical variables, each divided into categories based on percentiles. Cows that had a transition to UCD at the first observation after a missing observation due to dry period were excluded, because the onset of UCD for these cows could have been late in the previous lactation or early in the current one, as the cows were not observed when they were in dry period. In addition, cows that had missing values for an explanatory variable were excluded when that variable was in the model. Explanatory variables with $P \leq 0.2$ were tested for collinearity by Spearman rank correlations. If $\mathrm{r} \geq 0.7$, only one variable, the one with the lowest $P$-value in the univariable analysis, was kept for the multivariable model. The multivariable model was built using a manual stepwise, backward process, in which all explanatory variables were included from the beginning, and then removed if: (1) their $P$-value was $>0.05$, and (2) the model showed better quality when tested with Akaike's information criterion without that specific variable. All plausible 2-way interactions between the remaining explanatory variables in the model were tested. Model fit was assessed by visual evaluation of residual plots according to Dohoo et al. (2010).

For investigating factors affecting transitions to mild UCD, the model was built in the same way as the model for any type of UCD, including cows with no UCD at 
the previous observation and mild UCD (yes or no) as a binary outcome. Observations of severe UCD were excluded from this data set.

For transitions to severe UCD, the model was also built in the same way as for any type of UCD, with a few exceptions, and with severe UCD (yes or no) as a binary outcome. Cows with no, or mild, UCD at the previous observation (i.e., the previous herd visit when the cow was observed) were included in the analyses. Having mild UCD at the previous observation was included as an explanatory variable for the outcome (severe UCD), and cows with several observations of severe UCD with observations of no or mild UCD in between could thus contribute to several observations of transitions from unaffected to severe UCD.

Associations Between Transitions to UCD and Veterinary-Treated Clinical Mastitis, Milk $S C C$, and Hock Lesions. Because previous studies (Persson Waller et al., 2014; Ekman et al., 2018) indicated associations between UCD and other health problems, such as mastitis and hock lesions, we wanted to investigate these associations in the current study by focusing on cows with recent transitions to any type of, mild, or severe UCD. Therefore, we carried out univariable, mixed-effect logistic regression analyses using 3 different binary outcomes: (1) veterinary-treated clinical mastitis (VTCM); (2) high milk SCC; and (3) hock lesions. A cow was positive for VTCM if she had a registration of VTCM (by the farmer or via the Swedish official milk recording scheme) within approximately 6 wk after the herd visit (after 1 observation of the cow, but before the next herd visit). High milk SCC was defined as a SCC of $\geq 200,000$ cells $/ \mathrm{mL}$, based on data from test-milkings within $45 \mathrm{~d}$ after the herd visit. Hock lesions (yes or no) were registered at the same time as the UCD observation. Any type of, mild, or severe UCD were tested as 3 separate explanatory variables for each outcome. Because the focus was on recent transitions to $\mathrm{UCD}$, just as for the risk factor analysis, only cows with no UCD at the previous observation were included in the analysis. In contrast, cows with no or mild UCD at the previous observation were included in those analyses in which severe UCD was the explanatory variable. Herd and cow were included as random effects in all models (equal variances, all covariances zero). If there was an indication of an association $(P \leq 0.1)$ between the explanatory and the dependent variable, breed and parity were added to the model to investigate potentially confounding effects on the explanatory variable. For the outcome milk SCC, the variables kilograms of ECM from the same test milking and DIM were also tested for confounding ef- fects. Only variables with a confounding effect on the explanatory variable (indicated by a change of $>20 \%$ in the point estimate of the coefficient) were kept in the final model. Spearman rank test was used to test collinearity between explanatory variables in all multivariable analyses. Model fit for all models was assessed by visual examination of residual plots for herd and cow residuals according to Dohoo et al. (2010).

Observed Duration of UCD Cases. To estimate the duration of UCD, cows with 6 or more observations (i.e., observed for at least 36 weeks) were included in a duration data set. A UCD case was defined as 1 or more consecutive observations of UCD. Cases that were preceded and followed by at least 1 observation of no UCD were considered to have known start and end, whereas the other UCD cases were considered to have unknown start or end, or both. Cows that had gaps (i.e., missing observations due to dry period and calving) were included in this data set if they had the same UCD status before and after the gap; otherwise they were excluded. A rough estimate of the duration of a UCD case was made based on the visit interval. Thus, a duration of a single UCD observation was translated into approximately $6 \mathrm{wk}$, a duration of 2 UCD observations translated into $12 \mathrm{wk}$, and so forth. The duration of cases involving only mild UCD observations was compared with the duration of cases involving at least 1 observation of severe UCD using Wilcoxon rank-sum (Mann-Whitney) test.

\section{RESULTS}

\section{Herd Visits and Observations}

Herd characteristics for the participating farms are presented in Table 2. In total, 6,221 observations of 1,106 individual cows were performed at 9 visits per herd during the 1-yr study period. The total number of cows examined in all 7 herds at each visit varied between 660 and 711 . The most common breeds were Swedish Red (SR; $\mathrm{n}=544)$ and Swedish Holstein $(\mathbf{S H}$; $\mathrm{n}=363)$. Other cows $(\mathrm{n}=199)$ were mainly $\mathrm{SR} \times \mathrm{SH}$ crossbreeds. The number of observations per cow varied between 1 and 9 (mean 5.6 observations per cow; Figure 1). Missing observations were due to cows entering or exiting the herd during the study period (e.g., heifers that calved, cows that were culled). Cows that were dried off, cows in sick pens that were not milked in the milking parlor, and cows that were missed or registered with incorrect cow ID by the observer during the herd visit, could also be missing for one or more herd visits and then re-enter the study at a later herd visit. Cows 
Table 2. Characteristics of the 7 Swedish dairy cattle herds included in the longitudinal study of udder cleft dermatitis (UCD)

\begin{tabular}{|c|c|c|c|c|c|c|c|}
\hline Herd & 1 & 2 & 3 & 4 & 5 & 6 & 7 \\
\hline Herd size $^{2}$ & 168 & 132 & 107 & 95 & 87 & $156^{3}$ & 129 \\
\hline Average production level ${ }^{4}$ & 11,534 & 11,350 & 10,523 & 11,195 & 8,713 & 10,431 & 7,680 \\
\hline Type of freestall & $\operatorname{Ins}^{7}$ & Unins $^{8}$ & Ins & Unins & Ins & Unins & Ins \\
\hline Type of milking parlor & $\mathrm{H}^{9}$ & $\mathrm{H}$ & $\mathrm{H}$ & $\mathrm{H}$ & $\mathrm{T}^{10}$ & $\mathrm{~T}$ & $\mathrm{H}$ \\
\hline
\end{tabular}

${ }^{1}$ Registered prevalence of UCD in a study performed in 2014-2015 (Ekman et al., 2018).

${ }^{2}$ Average number of cows for the study period, May 2018-April 2019 (data from the Swedish official milk recording scheme, SOMRS).

${ }^{3}$ Herd 6 milked approximately 90 cows in the milking parlor, and approximately 60 cows in an automatic milking system (AMS). The cows in the AMS were not included in the study.

${ }^{4}$ Average $\mathrm{kg}$ of ECM per cow and year for the study period (data from SOMRS).

${ }^{5} \mathrm{C}=$ conventional.

${ }^{6} \mathrm{O}=$ organic.

${ }^{7}$ Ins $=$ insulated.

${ }^{8}$ Unins $=$ uninsulated.

${ }^{9} \mathrm{H}=$ herringbone milking parlor.

${ }^{10} \mathrm{~T}=$ tandem milking parlor.

that were observed only once $(\mathrm{n}=87)$ were excluded from further analyses, leaving 1,019 cows with 2 or more observations (mean 6.0 observations per cow).

The overall prevalence, including cows from all herds, of any type of, mild, and severe UCD, varied between visits, from 22 to $29 \%$ for any type of UCD, from 12 to $19 \%$ for mild UCD, and from 7 to $11 \%$ for severe UCD. Most cows $(69 \%, 704$ of 1,019) with at least 2 observations had the same status at all their observations: no UCD $(\mathrm{n}=608)$ or any type of UCD ( $\mathrm{n}=$ 96). Table 3 gives the number of transitions between the different categories (no, mild, and severe), whereas Supplemental Table S1 (https://doi.org/10.3168/jds
.2019-17935) shows all transitions between the detailed categories (score 0-5). The prevalence of UCD varied more between herds than between visits within the herd, and no clear seasonal pattern was detected in UCD prevalence (Figure 2).

\section{Incidence of New UCD Cases}

For all herds and all visits, the mean overall incidence rate of observed new cases of any type of UCD was 0.51 (CI $0.45-0.59)$ per cow-year at risk. The overall subincidence rates of mild and severe UCD were 0.41 (CI $0.36-0.48$ ) and 0.18 (CI $0.15-0.22$ ) cases per cow-year

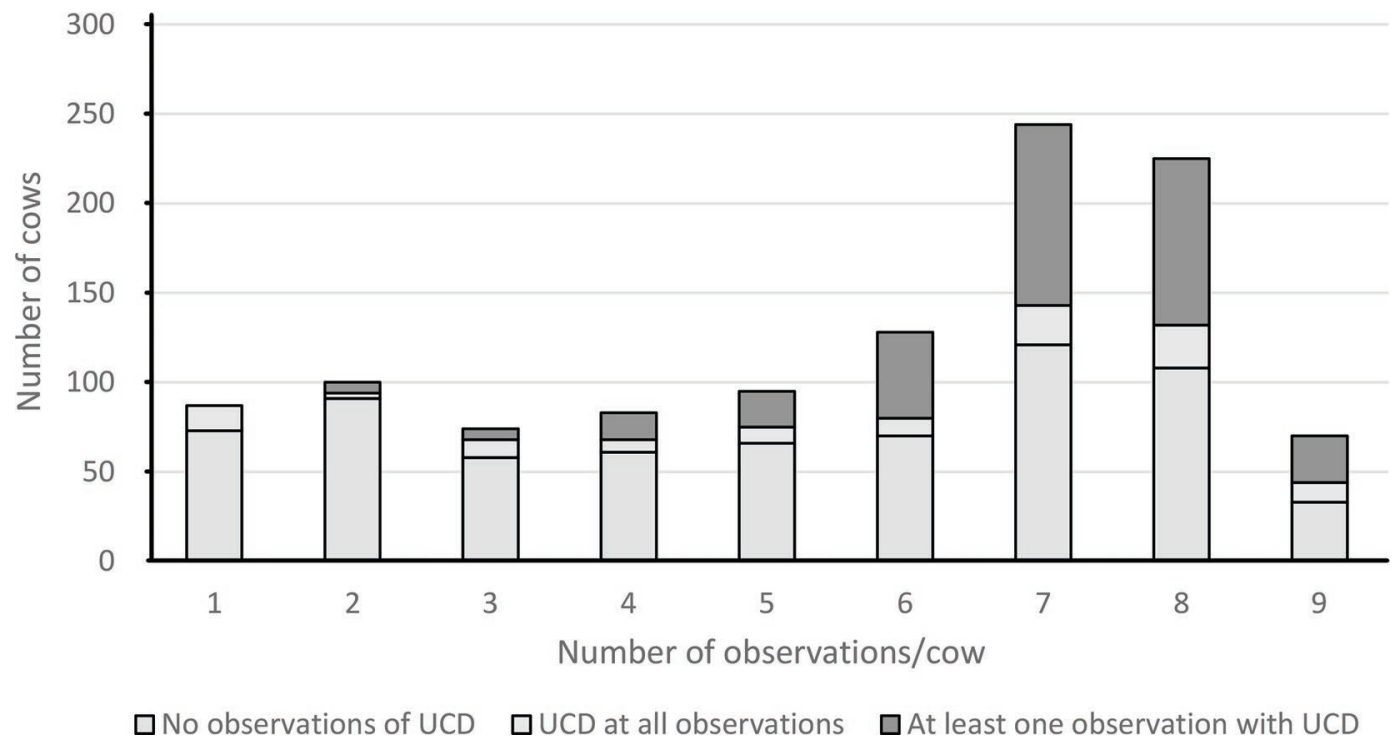

Figure 1. Distribution of cows with no udder cleft dermatitis (UCD), UCD at all, and UCD upon at least 1, but not all, observations. The cows were observed 1 to 9 times during herd visits at 6 -wk intervals throughout the 1 -yr study period. 
at risk, respectively. The incidence rates of observed new cases of different types of UCD for each herd are presented in Table 4. The within-herd incidence rates varied between visits but showed no clear temporal pattern (data not shown). In the comparison of withinherd incidence rates between visits for mild and severe $\mathrm{UCD}$, a relatively high incidence of mild UCD at one visit, followed by a relatively high incidence of severe UCD at the subsequent visit, was observed in several herds.

\section{Risk Factors Associated with Transitions to UCD}

The results of the multivariable analyses of cow-level risk factors for any type of, mild, or severe UCD are presented herein. Risk factors for each type of UCD investigated in univariable analyses are presented in Supplemental Table S2; https://doi.org/10.3168/jds .2019-17935. These factors included udder conformation, hygiene, parity, breed, DIM, results from test milkings, and veterinary-treated disorders during the study period. For severe UCD, having mild UCD at the previous observation was also included as a risk factor.

Any Type of UCD. The univariable analyses of any type of UCD included between 3,199 and 3,533 observations of 810 to 861 cows, depending on explanatory variable. In total, 8 out of 16 variables had $P \leq$ 0.20 in the univariable analyses and were included in the multivariable model (Supplemental Table S2). The final model was based on 3,319 observations of 849 cows, with 4 explanatory variables: breed, DIM, I/F at the fore udder attachment, and milk urea (Table 5). The risk for a transition to UCD increased linearly with an odds ratio (OR) of 1.4 per 100 DIM. Cows with a milk urea level below $3.7 \mathrm{mmol} / \mathrm{L}$ had a lower risk for a transition to UCD than cows in the other milk urea categories. In addition, an interaction was seen between breed and $\mathrm{I} / \mathrm{F}$ at the fore udder attachment (Figure 3). Among cows without an $\mathrm{I} / \mathrm{F}$ at the fore udder attachment, the risk for a transition to UCD was higher for SR cows than for SH cows (OR 3.6, $P=$ 0.001 ) and tended to be higher for SR cows compared with other breeds (OR 2.1, $P=0.07$ ). However, no difference in risk between breeds was found for cows with an I/F. Within breed, for other breeds and for SH cows, the presence of an $\mathrm{I} / \mathrm{F}$ at the fore udder attachment increased the risk for a transition from unaffected to UCD with an OR of $4.4(P=0.002)$ for other breeds, and $3.7(P=0.001)$ for $\mathrm{SH}$ cows, compared with cows of the same breeds without I/F. However, an I/F did not increase the risk for SR cows $(P=0.12)$ compared with SR cows without I/F.

Mild $U C D$. For mild UCD, 8 out of 16 tested variables had $P<0.20$ and were included in the multivariable model (Supplemental Table S2). The final model of risk factors for a transition to mild UCD included 3,290 observations of 845 cows, and the results were similar to those of any type of UCD. Retained variables were DIM, milk urea level, and an interaction between breed and $\mathrm{I} / \mathrm{F}$ at the fore udder attachment (Supplemental Table S3; https://doi.org/10.3168/jds.2019-17935). As for any type of UCD, the risk for a transition to mild UCD increased with DIM and decreased if the cow had a low milk urea level. Also, the effect of the interaction between breed and I/F was similar to what was seen for any type of UCD.

Severe UCD. For severe UCD, 6 out of 17 screened variables had $P<0.20$ in the univariable analyses (Supplemental Table S2). The final model included

Table 3. The number of transitions between categories (none, mild, or severe) of udder cleft dermatitis (UCD), during 1 yr, with 9 visits per herd in 7 Swedish dairy herds; the total number of transitions were 5,115 in 1,019 cows

\begin{tabular}{llrr}
\hline $\begin{array}{l}\text { UCD status at previous } \\
\text { observation }(\mathrm{x}-1)\end{array}$ & $\begin{array}{l}\text { UCD status at subsequent } \\
\text { observation }(\mathrm{x})\end{array}$ & $\mathrm{N}^{1}$ transitions & $\%^{2}$ \\
\hline No UCD $(\mathrm{n}=3,899)$ & No UCD & 3,563 & 91.4 \\
& Mild UCD & 285 & 7.3 \\
& Severe UCD & 51 & 1.3 \\
Mild UCD $(\mathrm{n}=789)$ & No UCD & 225 & 28.5 \\
& Mild UCD & 484 & 61.3 \\
Severe UCD $(\mathrm{n}=427)$ & Severe UCD & 80 & 10.1 \\
& No UCD & 22 & 5.1 \\
& Mild UCD & 92 & 21.5 \\
& Severe UCD & 313 & 73.3
\end{tabular}

${ }^{1} \mathrm{~N}=$ number of transitions (cows with a previous observation that either retained or changed their UCD status at the subsequent observation).

${ }^{2}$ Proportion (\%) of cows within each UCD status group (based on numbers of cows at the previous observation). 
Herd 1
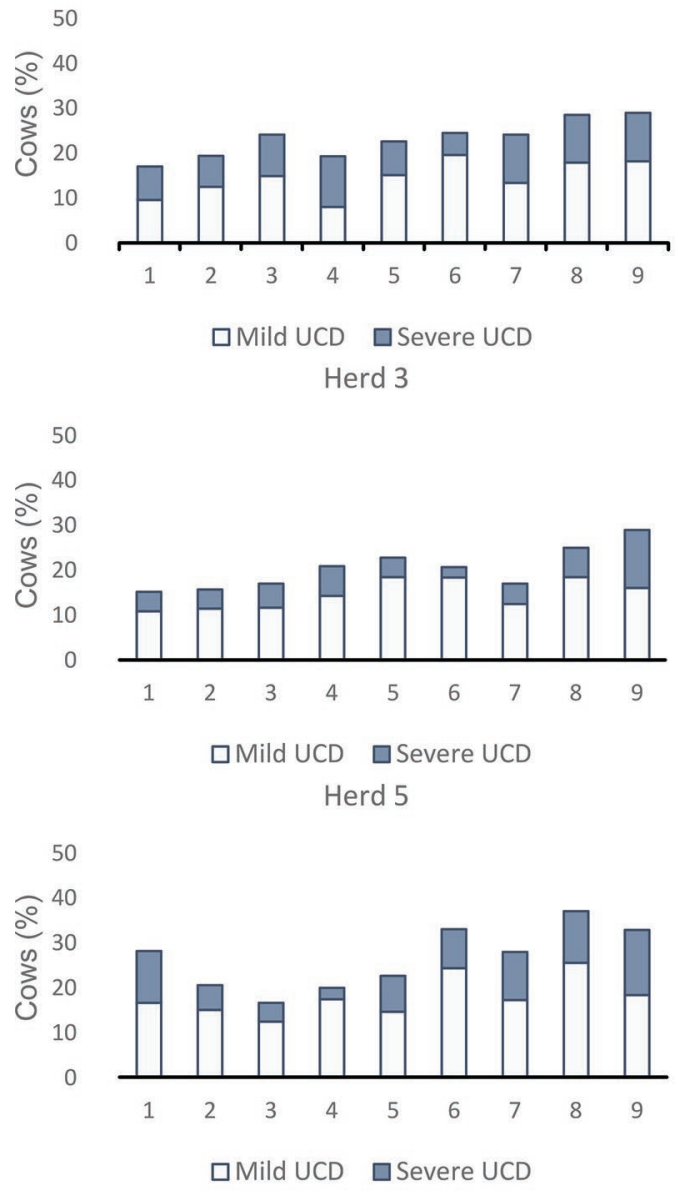

Herd 7

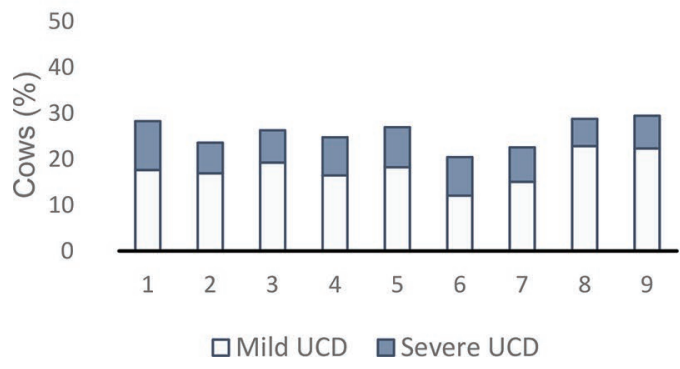

Herd 2
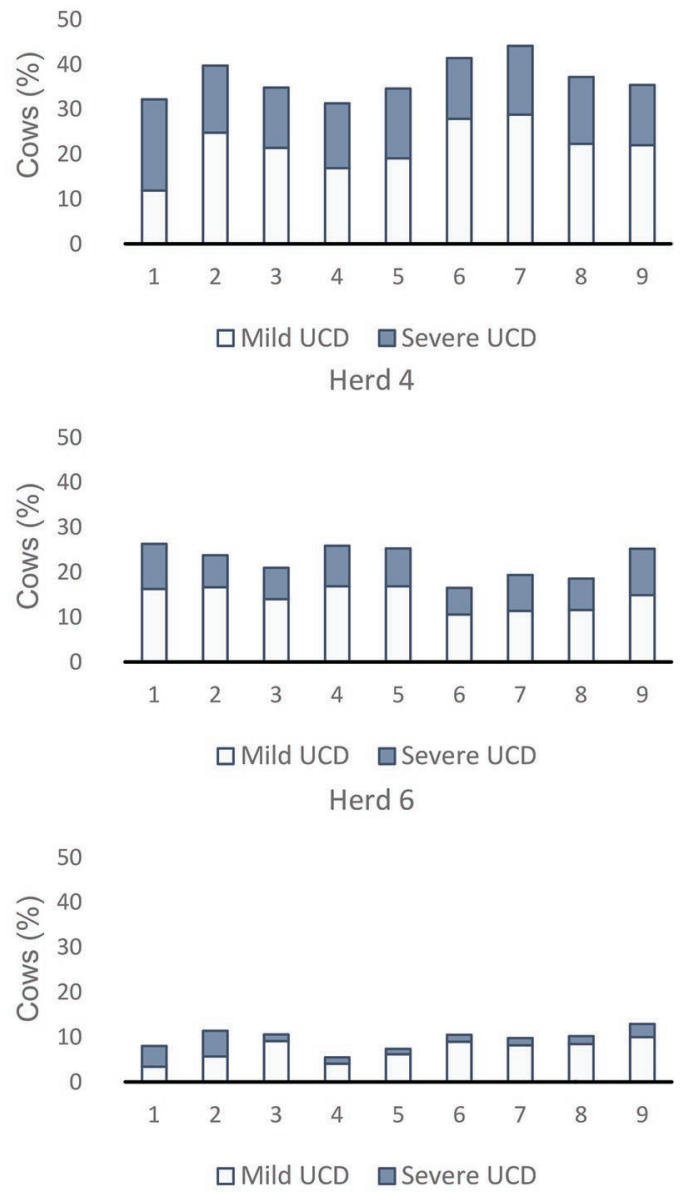

Figure 2. Proportions of cows affected by mild and severe udder cleft dermatitis (UCD) at 9 herd visits in 7 herds at 6-wk intervals during a 1-yr longitudinal study performed April 2018 to April 2019.

4,091 observations of 937 cows, and 3 variables were retained: production level, mild UCD at the previous observation, and parity (Table 6). The risk for a transition to severe UCD was higher for cows producing more than $39.7 \mathrm{~kg}$ compared with cows that produced less than $24.7 \mathrm{~kg}$ (OR 3.8, $P=0.009)$. The high-producing cows $(>39.7 \mathrm{~kg})$ also had higher risk for a transition to severe UCD than did cows producing 24.7 to $29.6 \mathrm{~kg}$ (OR 2.6, $P=0.03$ ). The risk for a transition to severe
UCD was also higher for cows that had mild UCD at the previous observation, compared with those that did not (OR 16.0, $P<0.001$ ). A tendency toward lower risk for a transition to severe UCD was identified for cows in second compared with first parity (OR 0.4, $P=$ $0.02)$, but the variable was not overall significant $(P=$ 0.08). However, it was kept in the model, as the Akaike information criterion indicated better quality when it was included. 
Table 4. Incidence rate (cases per cow-year at risk) of observed new cases of any type of, mild, and severe udder cleft dermatitis (UCD) in 7 Swedish dairy herds visited 9 times throughout $1 \mathrm{yr}^{1}$

\begin{tabular}{|c|c|c|c|c|c|c|c|}
\hline \multirow[b]{2}{*}{ Item } & \multicolumn{7}{|c|}{ Herd } \\
\hline & 1 & 2 & 3 & 4 & 5 & 6 & 7 \\
\hline \multicolumn{8}{|l|}{ Any type } \\
\hline Mean & 0.71 & 0.82 & 0.46 & 0.29 & 0.58 & 0.16 & 0.44 \\
\hline $95 \%$ CI & $0.55-0.90$ & $0.62-1.09$ & $0.3-0.7$ & $0.18-0.49$ & $0.39-0.85$ & $0.08-0.32$ & $0.30-0.63$ \\
\hline \multicolumn{8}{|l|}{ Mild } \\
\hline Mean & 0.52 & 0.69 & 0.41 & 0.24 & 0.44 & 0.14 & 0.36 \\
\hline \multicolumn{8}{|l|}{ Severe } \\
\hline Mean & 0.23 & 0.27 & 0.15 & 0.13 & 0.22 & 0.04 & 0.18 \\
\hline $95 \%$ CI & $0.16-0.34$ & $0.18-0.42$ & $0.08-0.27$ & $0.07-0.26$ & $0.13-0.39$ & $0.01-0.15$ & $0.11-0.29$ \\
\hline
\end{tabular}

${ }^{1}$ Cows were "at risk" from the first observation of that individual cow, and time was calculated as days from that first observation. The incidence rate was calculated by dividing the observed new UCD cases by the total number of cows and days in the same period, and transformed into cases per cow-year at risk. In the mild UCD data set, cows classified with severe UCD were excluded. For severe UCD, cows with no, or mild, UCD were included as cows "at risk."

\section{Associations Between Transitions to UCD and VTCM, Milk SCC, and Hock Lesions}

No significant associations were found between the explanatory variables "transition to any type of UCD" or "transition to mild UCD" and VTCM $(P=0.07$ and 0.61, respectively; Supplemental Table S4; https:/ /doi.org/10.3168/jds.2019-17935). A recent transition to severe UCD, however, increased the odds for VTCM (OR 5.3; CI 1.9-14.7; $P=0.001$ ). This effect was also seen when the potential confounders breed and parity were included in the model. Parity had a significant effect on the risk of VTCM, whereas breed did not. No significant associations were seen between SCC or the presence of hock lesions and any of the explanatory variables (Supplemental Table S4).

\section{Observed Duration of UCD Cases}

In total, 672 cows had 6 or more observations. Of these cows, 336 had at least 1 observation of UCD, whereof 19 were excluded, as they changed UCD status during the dry period. Thus, 317 cows were included in the description of the duration. Each cow had 1 to 4 UCD cases, with a total number of 416 observed cases. For all cases of UCD, the observed median duration was $12 \mathrm{wk}$ (range $6-54 \mathrm{wk})$. Only $24 \%(\mathrm{n}=100)$ of the observed cases had known start and end; the me-

Table 5. Factors associated with transitions to any type of udder cleft dermatitis (UCD) in the final multivariable mixed-effect logistic regression analysis, based on 3,319 observations of 849 cows; herd and cow were included as random factors

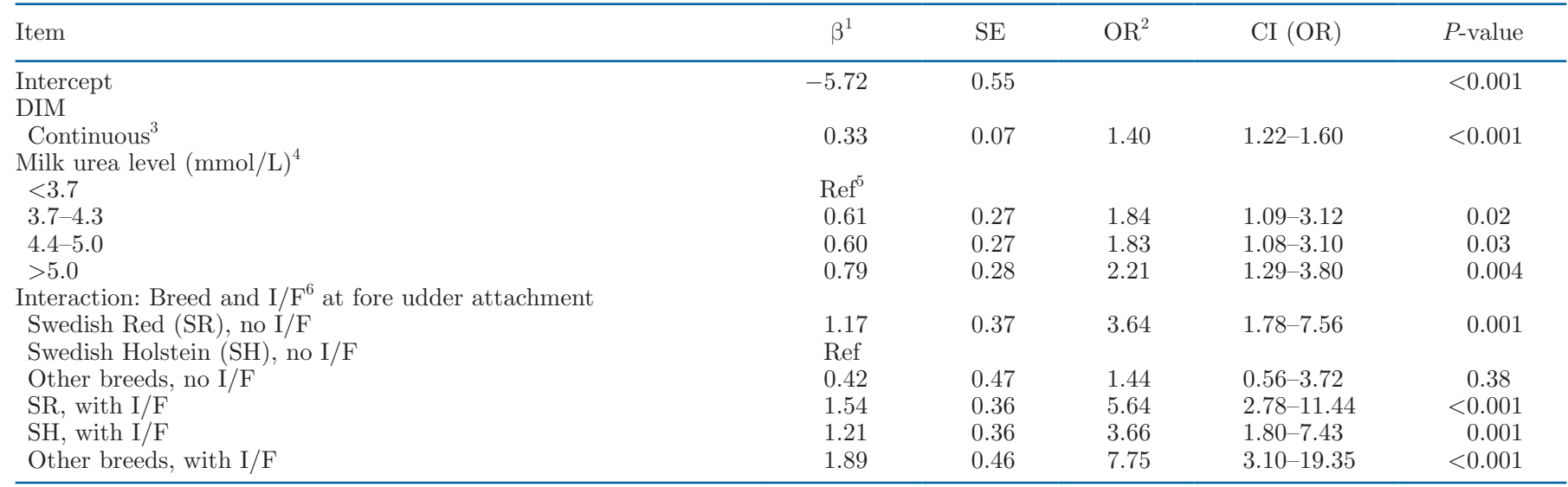

${ }^{1} \beta=$ regression coefficient.

${ }^{2} \mathrm{OR}=$ odds ratio

${ }^{3}$ Days since calving divided by 100

${ }^{4}$ Based on data from test milkings within $31 \mathrm{~d}$ before the herd visit (data from the Swedish official milk recording scheme, SOMRS).

${ }^{5}$ Ref $=$ reference category.

${ }^{6} \mathrm{I} / \mathrm{F}=$ indentation or fold at the fore udder attachment observed at herd visit. 


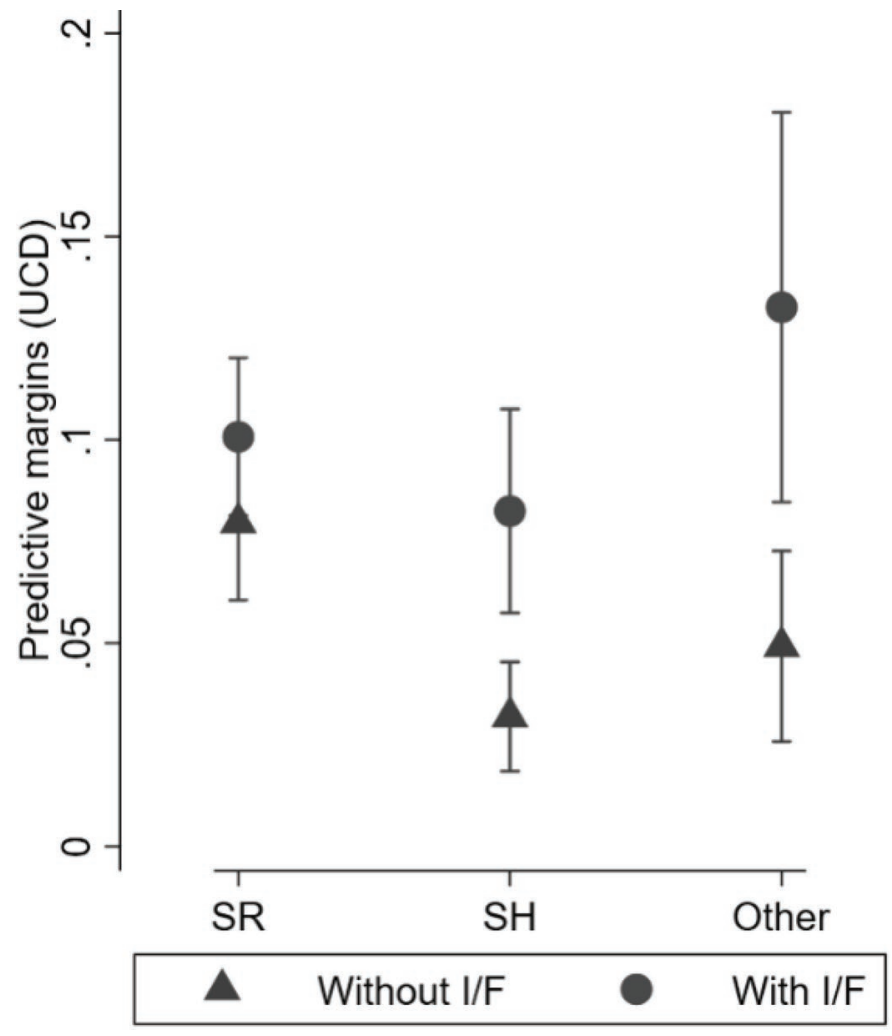

Figure 3. Predictive margins of the risk of a transition to udder cleft dermatitis (UCD), and associated risk factors. An interaction was seen between breed and the udder conformation trait indentation or skin fold (I/F) at the fore udder attachment. Whiskers indicate $95 \%$ CI, based on a multivariable mixed-effect logistic regression model with 3,319 observations of 849 cows in 7 Swedish dairy herds. SR = Swedish Red; $\mathrm{SH}=$ Swedish Holstein. dian observed duration for those cases was 6 wk (range 6-36 wk); and only $3 \%(\mathrm{n}=3)$ of the observed cases included severe UCD. The median duration of UCD cases including only mild UCD was 6 wk (range 6-54), which was shorter than for cases including severe UCD $(P<0.001)$, where the median was 30 wk (range $6-54$; Figure 4).

\section{DISCUSSION}

This longitudinal study provides an important contribution to the understanding of the incidence and duration of UCD in herds with high prevalence of UCD. The study identified certain cow-level risk factors associated with transitions to UCD and found an interesting association between severe UCD and VTCM.

\section{Incidence of Observed New UCD Cases}

The overall incidence of observed new cases of any type of UCD found in the present study was 0.51 cases per cow-year at risk. This is equal to 0.98 cases per 100 cow-weeks at risk, and is somewhat lower than the incidence of 1.94 cases per 100 cow-weeks at risk observed by Bouma et al. (2016); however, in that study, a different visit interval was used, which could influence the results. The incidence found in our study is high compared with common production diseases such as mastitis, with an overall incidence of 0.09 cases per cow-year in Sweden from 2017 to 2018 (Växa Sverige, 2019). The herds in this study, however, were known to have a medium to high prevalence of UCD. Because

Table 6. Factors associated with transitions to severe udder cleft dermatitis (UCD) in the final multivariable mixed-effect logistic regression analysis, based on 4,091 observations of 937 cows; herd and cow were included as random factors

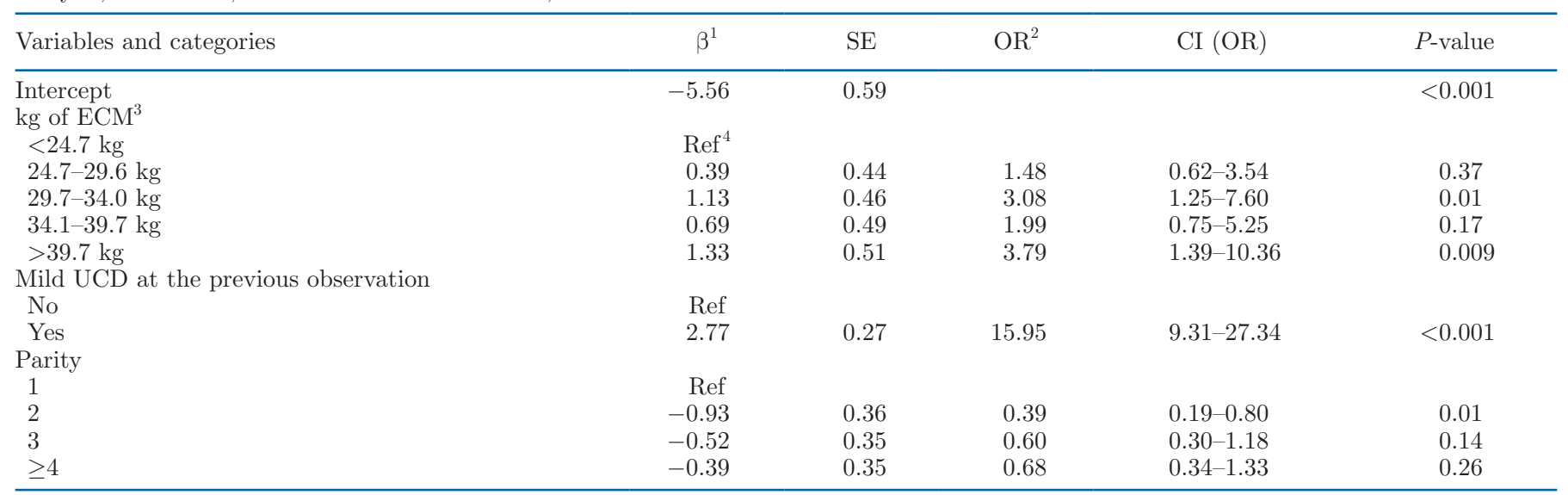

${ }^{1} \beta=$ regression coefficient.

${ }^{2} \mathrm{OR}=$ odds ratio.

${ }^{3}$ Based on data from test milkings within $31 \mathrm{~d}$ before herd visit (data from the Swedish official milk recording scheme, SOMRS).

${ }^{4}$ Ref $=$ Reference category 
the incidence rate in combination with the duration of the lesions affects the prevalence of UCD in the herd, it is likely that the herds in our study have a higher incidence rate than the average Swedish dairy herd. Moreover, the calculated incidence in the present study was based on the first observed UCD case in the included cows and might not be true "new" cases of $\mathrm{UCD}$, as recurrent cases appear to be common. The within-herd incidences of observed new cases of any type of UCD had no clear pattern but varied markedly between visits, the reasons for which are not known.

For most herds in our study, the prevalence of mild UCD fluctuated more between visits than did the prevalence of severe UCD. This might be due to recurrent cases of mild UCD and to the fact that mild cases had shorter duration than severe cases. It is also possible that mild lesions can vary in appearance and, not unlike atopic dermatitis in humans (Ahn and Huang, 2017), flare up periodically. If a mild UCD case was located within a skin fold, a risk exists that it was missed during one or several observations. However, palpation was used in most observations to avoid this bias. To increase knowledge on recurrence and recovery of UCD, further studies on cow-level risk factors should be performed.

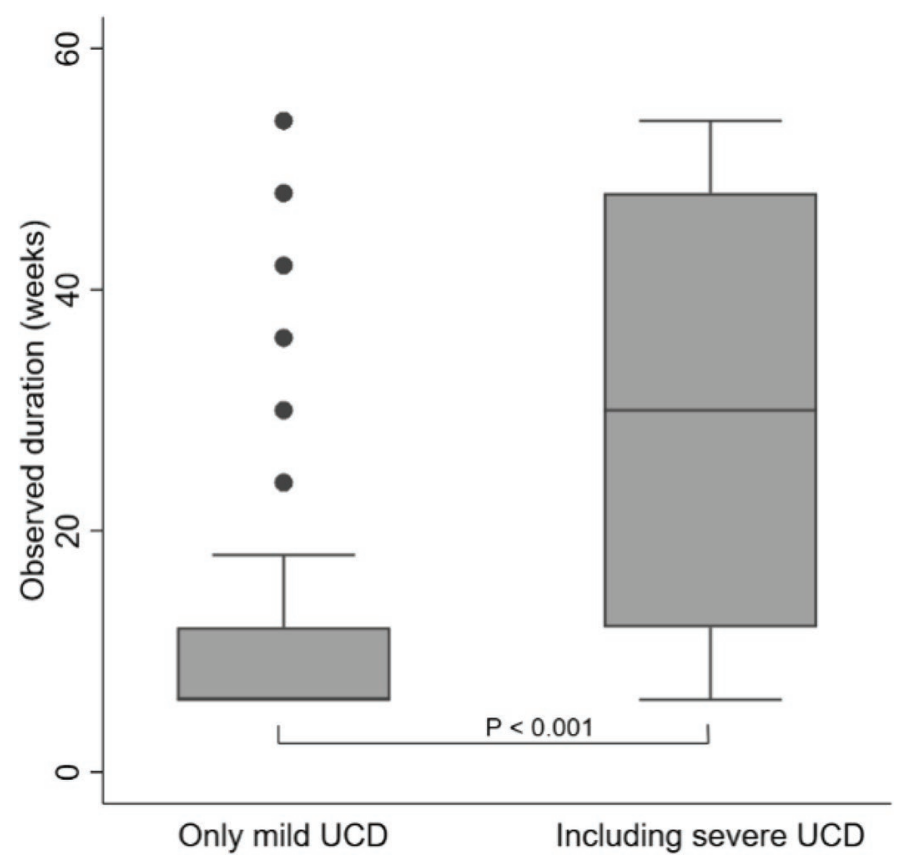

Figure 4. Observed duration (wk) of cases involving mild (median: 6) udder cleft dermatitis (UCD) only or at least 1 observation of severe UCD (median: 36), between April 2018 and April 2019. Data included 416 cases of UCD in 317 cows from 7 herds that were observed 6-9 times throughout the study. The box shows the lower quartile, median, and the upper quartile, and the whiskers show the upper and lower adjacent values (1.5 interquartile range from the lower and upper quartile, respectively). The dots are outliers.

\section{Risk Factors Associated with Transitions to UCD}

To our knowledge, this is the first study investigating risk factors associated with the transition from unaffected to any type of, mild, or severe UCD. In contrast with previous studies, mostly cross-sectional, that analyzed risk factors for having UCD, we used a transition model approach. We found several risk factors for transitions to different types of UCD lesions. Most of the risk factors found in our study have also previously been identified in cross-sectional studies, which emphasizes their importance for the development of UCD lesions.

Any Type of UCD and Mild UCD. The fact that the same risk factors were seen for transitions from unaffected to any type of UCD and mild UCD was probably because the most common transition was from no UCD to mild UCD, which means that the data sets for the 2 analyses were similar. This could have led to overinterpretation of the risk factors for transitions to mild UCD in the model with any type of UCD.

Some risk factors found have also been identified as risk factors for having UCD in previous cross-sectional studies. These included higher risks for (1) SR than SH for cows (Persson Waller et al.; 2014; Ekman et al., 2018); (2) cows with an I/F at the fore udder attachment (Persson Waller et al.; 2014; Ekman et al., 2018); and (3) increasing DIM (Olde Riekerink et al., 2014; Persson Waller et al., 2014; Ekman et al., 2018). However, parity was not a risk factor in our study, although it has been identified as a risk factor in several cross-sectional studies on UCD (Warnick et al., 2002; Persson Waller et al., 2014; Ekman et al., 2018), as well as in a previous longitudinal study using survival analysis (Bouma et al., 2016). The reasons for this discrepancy might be related to the long duration of UCD, sometimes overlapping several lactations, leading to an accumulation of cases in older cows. In line with this, a substantial number of cows had the same UCD status at observations before and after dry period and calving, indicating that recovery from UCD during the dry period was rather uncommon (data not shown). It could also be that complex associations between parity, DIM, and udder conformation play a role in the development and duration of UCD.

The higher risk for SR cows compared with SH cows might also be related to udder conformation traits, as discussed by Ekman et al. (2018). We found that the presence of an $\mathrm{I} / \mathrm{F}$ at the fore udder attachment had a larger influence on the risk of any type of, and mild, UCD for SH and other breeds than for SR cows. A similar interaction between breed and udder conformation is reported by Ekman et al. (2018), who found that a strong fore udder attachment reduced the risk of severe 
UCD for SH but not for SR cows. If the general udder conformation of SR cows predisposes them to UCD, the investigated udder conformation traits would have a larger effect on $\mathrm{SH}$ cows and other breeds, which could explain the interactions discussed.

An interaction between parity and udder conformation (I/F at the fore udder attachment) was identified by Ekman et al. (2018) for mild UCD. This indicates that breed, parity, and udder conformation are closely linked and might affect the risk of UCD in relation to each other. In the longitudinal study by Bouma et al. (2016), a higher incidence of any type of UCD was found in older cows, but no association was detected between UCD and udder conformation. This might be because the udder conformation traits in their study were obtained from a breeding evaluation performed in the first lactation. It is well known that changes in udder conformation, resulting in looser fore udder attachment and increased udder depth, occur with increasing parity (Ral et al., 1988) and increasing DIM (Gustafsson, 1998). These udder conformation traits are associated with UCD in other studies (Hansen and Nissen, 2010; Olde Riekerink et al., 2014; Persson Waller et al., 2014), and they were significant in the univariable analyses in the present study but not in the final models. This indicates that, in our study, I/F at the fore udder attachment was more important as a risk factor for any type of, and mild, UCD than the other udder conformation traits. However, as discussed by others, changes in udder conformation that lead to increases of skin folds at the fore udder attachment and increased udder pressure can predispose for UCD (Beattie and Taylor, 2000; Persson Waller et al., 2014; Ekman et al., 2018). Udder pressure can result from the increase in its size after calving and associated edema.

A new finding was that low milk urea level $(<3.7$ $\mathrm{mmol} / \mathrm{L}$ ) was associated with a lower risk of a transition to any type of, and mild, UCD, something not seen in a previous cross-sectional study on UCD (Ekman et al., 2018). Milk urea level is an indicator of the protein balance of the feed, and the milk urea level should be 3.5 to $5.0 \mathrm{mmol} / \mathrm{L}$, to facilitate optimal absorption of nutrients in the feed, according to Swedish recommendations (Växa Sverige, 2019). A low urea level is indicative of a low protein content in the feed. In human medicine, diet is known to affect skin conditions, including atopic dermatitis (Katta and Kramer, 2018; Bonamonte et al., 2019). The importance of this risk factor needs to be further investigated. It is also possible that it is a spurious finding due to a type I error; that is, identification of a risk factor even though no true association exists, due to multiple testing.

Severe $U C D$. For transitions to severe UCD, there were no risk factors in common with those for any type of, or mild, UCD. The single most important risk factor for a transition to severe UCD was having mild UCD at the previous observation. This association between mild and severe UCD was also illustrated by the number of transitions between mild and severe UCD, which were more common than transitions between healthy and severe UCD. This finding emphasizes the importance of preventing and curing mild lesions, even though these are harder to detect. A high production level was also associated with increased risk of a transition to severe UCD, something also seen in previous cross-sectional studies, on both cow (Persson Waller et al., 2014; Ekman et al., 2018) and herd levels (Olde Riekerink et al., 2014; Persson Waller et al., 2014). Even though production level is not always linked to udder engorgement, the udder expands in early lactation and stretches the skin, subsequently impairing the skin barrier. Udder pressure and the presence of udder edema in early lactation may lead to reduced blood flow and impair the skin barrier at the fore udder attachment. These conditions are more likely in high-yielding cows. Blood flow measurements and histology of the udder skin in early lactation could therefore be of interest for understanding UCD etiology. Cows with a higher production level and increased negative energy balance have less resistance toward reproductive diseases, ketosis, and laminitis (Collard et al., 2000; Oltenacu and Broom, 2010), and it might be that they also are more prone to UCD. A negative energy balance, or malnutrition, is also associated with impaired wound healing in humans (Barbul and Purtill, 1994; Harris and Fraser, 2004; Stechmiller, 2010).

We also found a weak association between severe UCD and parity, with first-parity cows having a higher risk for severe UCD than second-parity ones. This is the opposite of findings regarding parity in previous studies (Warnick et al., 2002; Persson Waller et al., 2014; Bouma et al., 2016). Persson Waller et al. (2014) did, however, find a higher risk for severe UCD in secondparity cows than in cows in their third parity or higher. The higher risk for a new case of UCD in earlier parities might reflect the chronic nature of severe UCD, as well as the risk for recurrence once a cow has become affected by UCD, leading to a cumulative higher prevalence in older cows and, hence, a lower risk of a new case of UCD. However, the other risk factors found for severe UCD - high milk yield and previous mild UCD — might also be more common in older cows, which could affect the association between severe UCD and parity in this particular model. Because older cows produce more milk than first- or second-parity cows, the increased risk for cows with high milk yield might have affected the risk of parity. This finding is difficult to evaluate, and we cannot be sure of its importance. The model 
for severe UCD explained about $17 \%$ of the variation in the data set (data not shown), which is considerably higher than for mild UCD but still indicates that other, unidentified, factors may be of importance.

\section{Associations Between Transitions to UCD and VTCM, Milk SCC, and Hock Lesions}

The only significant association found between transitions to UCD and the investigated outcomes was that a transition to severe UCD increased the risk of VTCM within 6 wk after the UCD observation. This is in line with the results of a cross-sectional study by Persson Waller et al. (2014), which reported an association between having any type of UCD and VTCM within $30 \mathrm{~d}$ of the UCD observation. A recent Swedish study found no association between UCD and VTCM at cow level (Ekman et al., 2018). However, it did find a higher risk of severe UCD associated with a high herd incidence rate of VTCM, as well as a high herd rate of culling due to udder health problems. In the present study, the VTCM occurred after the onset of UCD, but the causality is unclear. Bacteria present in severe UCD lesions may increase the risk of bacterial intramammary infection due to the proximity of the UCD site and the teat canals. However, it is not known whether mastitis-causing pathogens are a common part of the bacterial flora of UCD lesions. Common risk factors for UCD and VTCM, such as impaired immune status, might also explain the finding. Further research on this association is warranted, as well as bacteriological investigations of UCD lesions. We found no association between transitions to UCD and SCC, which is in line with previous results (Persson Waller et al., 2014; Ekman et al., 2018). This indicates that factors other than the presence of UCD are more important for SCC.

We found no association between UCD and hock lesions. This is in contrast with the cross-sectional study by Ekman et al. (2018), which found an association between mild UCD and hock lesions at the same observation. However, the prevalence of hock lesions was higher in the present study (data not shown), and statistical methods differed between the studies. The fact that presence of hock lesions was scored only on the outside of 1 hock could have led to missed observations of hock lesions. However, because the prevalence of hock lesions was high (only $9 \%$ of observations indicated no hock lesions; data not shown), and because hock lesions often are bilateral (Potterton et al., 2011), we do not believe that this had any large influence on the study results. In addition, the high prevalence of hock lesions entails a low variance for this variable in the statistical analyses, which also could have affected the results.

\section{Observed Duration of UCD Cases}

The absolute majority of UCD cases with a known start and end had a short duration (i.e., only 1 observation of UCD, translated into approximately $6 \mathrm{wk}$ ). However, bcause most cases had unknown start and end dates, it is very likely that the overall duration was underestimated. Our results are in line with those of Bouma et al. (2016), who found that the overall median duration was $16 \mathrm{wk}$, including cases both with and without observed start and end. In that study, herd visits were performed at 1- or 2-wk intervals, which gives a better approximation of the exact duration than in our study. However, because Bouma et al. (2016) found that most cows did not change UCD status between 2 consecutive visits, the results of our study can probably be used as a rough estimate of UCD duration. Several cows had recurrent cases of UCD, which indicates that cows that have had UCD once are likely to get it again. Cows with observations of severe UCD had longer duration than those with only mild UCD, as also observed by Bouma et al. (2016), who found that the mean durations for mild and severe UCD episodes were 8.8 and $16.2 \mathrm{wk}$, respectively. As they suggested, this may reflect that the healing of open wounds is a slow process. In addition, severe lesions could be colonized by bacteria that may produce biofilm and impair healing, a process often seen in human chronic wounds (Wu et al., 2019).

\section{Methodological Considerations}

The herds included in the study were a convenience sample, to facilitate herd visits and to ensure enough cases of UCD throughout the study period. They might not be representative for the average Swedish dairy herd. However, as the study focused on cow-level risk factors, with herd accounted for as a random factor in the statistical models, the results might be valid for all Swedish dairy cows or, perhaps more likely, for cows in herds with a medium-to-high prevalence of UCD. In addition, although the sizes of most of the included herds were close to the Swedish average (92 cows in 2019; Växa Sverige, 2019), the range of herd sizes in the included herds was narrow, and the results may therefore not be valid for smaller or larger herds. The farmers were asked not to use any topical treatment on UCD lesions during the study period. Considering that this was according to their usual management and no effective treatment regimens are known in Sweden, we do not believe that this introduced any bias.

The visit interval of $6 \mathrm{wk}$ was based on practical reasons. More frequent visits would have been prefer- 
able to determine duration and incidence of UCD in more detail. However, even though our visit interval was longer than the 1- to 2-wk interval used by Bouma et al. (2016), most cows had the same status (no, mild, or severe UCD) for 2 consecutive observations in both the studies. The mean durations in the 2 studies are also rather similar, even though our data are a more rough evaluation of the exact duration. In addition, several cows had UCD when entering or exiting the study, and some had UCD throughout the entire study period, which also makes the duration difficult to evaluate. The majority of cases with a known start and end point were short, and for the other cases, duration can only be approximated based on the number of observations (i.e., number of weeks) that the cow had observed UCD. However, this is probably a severe underestimation of the actual duration, and a longer study period would have been required to determine the true duration of UCD.

Few cows were observed at all 9 herd visits, either because they entered the study at a later time (e.g., heifers that calved during the study period) or because they exited before the last herd visit (e.g., due to culling or drying off). In addition, cows that were dried off, put in sick pens, or missed by the observer at herd visits could lack data for one or several visits but then re-enter the study at a later herd visit. For practical reasons, it was not possible to observe cows during the dry period. However, the observations before and shortly after calving indicated that the UCD lesions often persisted throughout the dry period, as it is not likely that they healed and then reoccurred with a similar appearance shortly after calving. These conditions are expected in field studies and make the analyses of duration and risk factors more difficult. To make best use of the longitudinal data set and to focus on recently developed cases of UCD, we therefore used the transition model approach. This approach might lead to overinterpreting results from cows that remained in the study for a long time and had recurrent cases of UCD, and even though the random effect of cow was included, this may have introduced some bias in the analyses. In addition, when many risk factors are tested, the risk of type I errors increases (significant results despite no true association). Therefore, the results should be interpreted with caution and should be related to previously performed studies as well as to their biological plausibility.

No common definition for UCD exists, but several studies have used similar definitions of mild and severe UCD (Persson Waller et al., 2014; Bouma et al., 2016; Ekman et al., 2018). In the present study, we used a more detailed scoring system but found that this scoring led to small groups of cows within certain
UCD score categories, and thus coded the categories to better correspond with previous studies. We classified score 1 as no UCD because score 1 often referred to a single papule or pustule, which could have been caused by an insect or tick bite rather than UCD, or to redness of the skin that was difficult to interpret. Thus, we chose to regard cows with score 1 as unaffected, even though this might have led to misclassification for some cows that actually had mild UCD. However, this might have led to an over-interpretation of recurrent cases, because lesions scored as 1 could refer to an active lesion with very mild symptoms, or could be on the verge between score 1 and 2 , which probably affected the results, as cows with score 1 between 2 observations of score 2 would be defined as a recurrent case. Thus, for the incidence calculation, cows could contribute to only 1 new event (observed new UCD). The classification of score 3 as a severe lesion despite lack of an open wound was based on previous categorization in a cross-sectional study (Ekman et al., 2018). We also considered the presence of large crusts to be indicative of a breach of skin integrity, even if there was no open wound. The presence of only large crusts without an open wound was unusual, and score 3 was the least frequent throughout the study period (data not shown), so we do not believe that the classification of score 3 as severe UCD had any substantial effect on the results of this study.

\section{CONCLUSIONS}

The overall incidence of UCD in the study was high, and a large variation in incidence rates between herds and visits was detectable. Large variations also occurred in duration patterns and transitions between different types of UCD for individual cows. The number of these transitions indicates that severe lesions are usually preceded or followed, or both, by mild lesions. Several cows had recurrent cases of UCD, which, in combination with the often chronic nature of the lesions, indicates that cows that get UCD are likely to suffer from it for a long time. Breed and udder conformation are important risk factors for any type of, and mild, UCD, as has been established in previous studies, whereas production level affected the risk for a transition to severe UCD. Having a mild UCD lesion was an important risk factor for a transition to severe UCD. The complex associations between breed, udder conformation, production level, and parity may synergistically affect the risk of a transition to UCD. The actual causes of new UCD lesions are still not clear, and further studies on the microbiota and skin histology of healthy udders and udders with UCD lesions are warranted, to better understand the etiology 
of UCD. The findings in this study emphasize the need for preventive measures and treatment strategies for both mild and severe UCD.

\section{ACKNOWLEDGMENTS}

This study was funded by the Swedish Research Council Formas (Stockholm, Sweden) and Stiftelsen Lantbruksforskning (the Swedish farmers' foundation for agricultural research; Stockholm, Sweden). The authors thank the participating farmers for their hospitality and assistance throughout the study period. We are also grateful to Ulf Emanuelson (Swedish University of Agricultural Sciences, Uppsala, Sweden) and Ian Dohoo (University of Prince Edward Island, Charlottetown, Canada) for statistical advice and to Elisabeth Bagge (The National Veterinary Institute, Uppsala, Sweden) for helpful comments on the manuscript. The authors have not stated any conflicts of interest.

\section{REFERENCES}

Ahn, C., and W. Huang. 2017. Clinical presentation of atopic dermatitis. Adv. Exp. Med. Biol. 1027:39-46. https://doi.org/10.1007/ 978-3-319-64804-0_4.

Barbul, A., and W. A. Purtill. 1994. Nutrition in wound healing. Clin. Dermatol. 12:133-140. https://doi.org/10.1016/0738 -081X(94)90264-X.

Beattie, K. G., and D. J. Taylor. 2000. An investigation into intertrigo (necrotic dermatitis or 'foul udder') in dairy cows. Cattle Pract. $8: 377-380$.

Bonamonte, D., A. Filoni, M. Vestita, P. Romita, C. Foti, and G. Angelini. 2019. The role of the environmental risk factors in the pathogenesis and clinical outcome of atopic dermatitis. BioMed Res. Int. 2019:2450605. https://doi.org/10.1155/2019/2450605.

Bouma, A., M. Nielen, E. van Soest, S. Sietsma, J. van den Broek, T. Dijkstra, and T. van Werven. 2016. Longitudinal study of udder cleft dermatitis in 5 Dutch dairy cattle herds. J. Dairy Sci. 99:4487-4495. https://doi.org/10.3168/jds.2015-9774.

Collard, B. L., P. J. Boettcher, J. C. Dekkers, D. Petitclerc, and L. R. Schaeffer. 2000. Relationships between energy balance and health traits of dairy cattle in early lactation. J. Dairy Sci. 83:2683-2690. https://doi.org/10.3168/jds.S0022-0302(00)75162-9.

Dohoo, I., W. Martin, and H. Stryhn. 2010. Veterinary Epidemiologic Research. 2nd ed. VER Inc., Charlottestown, PEI, Canada.

Ekman, L., A. K. Nyman, H. Landin, U. Magnusson, and K. Persson Waller. 2018. Mild and severe udder cleft dermatitis - Prevalence and risk factors in Swedish dairy herds. J. Dairy Sci. 101:556-571. https://doi.org/10.3168/jds.2017-13133.

Gustafsson, Å. 1998. Genetiska studier av exteriöra juveregenskaper hos svenska mjölkkor. [Genetic studies of exterior udder traits of Swedish dairy cows]. MS thesis. Department of Animal Breeding and Genetics, Swedish University of Agricultural Sciences, Uppsala, Sweden
Hansen, M. J., and M. M. Nissen. 2010. A clinical study of udder cleft dermatitis on a Danish dairy farm. MS Thesis. Department of Large Animal Sciences, Faculty of Life Sciences, University of Copenhagen, Denmark.

Harris, C. L., and C. Fraser. 2004. Malnutrition in the institutionalized elderly: the effects on wound healing. Ostomy Wound Manage. 50:54-63.

Katta, R., and M. J. Kramer. 2018. Skin and diet: An update on the role of dietary change as a treatment strategy for skin disease. Skin Therapy Lett. 23:1-5.

Olde Riekerink, R. G. M., K. van Amersfort, O. C. Sampimon, G. A. Hooijer, and T. Lam. 2014. Short communication: Prevalence, risk factors, and a field scoring system for udder cleft dermatitis in Dutch dairy herds. J. Dairy Sci. 97:5007-5011. https://doi.org/10 $.3168 / j \mathrm{jds} .2013-7651$.

Oltenacu, P. A., and D. M. Broom. 2010. The impact of genetic selection for increased milk yield on the welfare of dairy cows. Anim Welf. 19:39-49.

Persson Waller, K., M. Bengtsson, and A. K. Nyman. 2014. Prevalence and risk factors for udder cleft dermatitis in dairy cattle. J. Dairy Sci. 97:310-318. https://doi.org/10.3168/jds.2013-7186.

Potterton, S. L., M. J. Green, K. M. Millar, C. J. Brignell, J. Harris, H. R. Whay, and J. N. Huxley. 2011. Prevalence and characterisation of, and producers' attitudes towards, hock lesions in UK airy cattle. Vet. Rec. 169:634-647. https://doi.org/10.1136/vr.d5491.

Ral, G., B. Berglund, J. Philipsson, U. Emanuelson, and G. Tengroth. 1988. Juver- och mjölkbarhetsegenskaper samt mjölkavkastning och mastitförekomst-Effekter av ras och ålder samt inbördes samband. [Udder- and milking capacity traits and milk yield and occurrence of mastitis - Effects of breed, age and intermutual associations]. Report 78. Department of Animal Breeding and Genetics, Swedish University of Agricultural Sciences, Uppsala, Sweden.

Sorge, U. S., E. M. Binger, J. Schefers, and P. J. Plummer. 2019. Short communication: Metagenomic evaluation of skin biopsies of udder sores in dairy cows. J. Dairy Sci. 102:11470-11475. https://doi .org/10.3168/jds.2018-15863.

Stechmiller, J. K. 2010. Understanding the role of nutrition and wound healing. Nutr. Clin. Pract. 25:61-68. https://doi.org/10.1177/ 0884533609358997.

Växa Sverige. 2019. Redogörelse för husdjursorganisationernas djurhälsovård 2017/2018. [Report on animal health care within the livestock organisation 2017/2018]. Accessed Nov. 20, 2019. https://www.vxa.se/globalassets/dokument/statistik/redogorelse -for-husdjursorganisationernas-djurhalsovard-2017-2018.pdf.

Warnick, L. D., D. Nydam, A. Maciel, C. L. Guard, and S. E. Wade. 2002. Udder cleft dermatitis and sarcoptic mange in a dairy herd J. Am. Vet. Med. Assoc. 221:273-276. https://doi.org/10.2460/ javma.2002.221.273.

Wu, Y. K., N. C. Cheng, and C. M. Cheng. 2019. Biofilms in chronic wounds: Pathogenesis and diagnosis. Trends Biotechnol. 37:505517. https://doi.org/10.1016/j.tibtech.2018.10.011

\section{ORCIDS}

L. Ekman (ㄱ https://orcid.org/0000-0002-6556-1111

A-K. Nyman @ (ttps://orcid.org/0000-0002-6643-0404

K. Persson Waller ๑ https://orcid.org/0000-0002-8481-4313 